\title{
Ensino de literaturas africanas em língua portuguesa em escolas de Campo Grande/MS
}

\author{
Cristiane da Silva Umbelino* \\ Danglei de Castro Pereira**
}

Resumo: O projeto tem o objetivo discutir aspectos teóricos/ metodológicos relacionados ao ensino de literaturas africanas em língua portuguesa em escolas da rede estadual de ensino em Campo Grande/MS. Centraremos nossa abordagem na legislação destinada ao ensino de literaturas em Língua portuguesa nos Parâmetros Curriculares Nacionais (PCN), na Lei de Diretrizes e Bases da Educação Brasileira (LDB); bem como nos Referenciais Curriculares da Educação Básica e do Ensino Médio de Mato Grosso do Sul. Daremos, em um segundo momento, enfoque a discussão de como a literatura africana em Língua portuguesa é tratada nestes textos, e investigaremos ações desenvolvidas nos últimos três anos para a melhoria do Ensino de Literaturas africanas em MS via discussão das Diretrizes Estaduais para o Ensino Médio, dando especial atenção para o Ensino de Literaturas em Língua Portuguesa no estado. Nossa preocupação é verificar a situação do ensino de Literaturas africanas de expressão em Língua Portuguesa.

Palavras-chave: Cânone literário; Literaturas africanas; Ensino de literatura

* Professora da Universidade Estadual de Mato Grosso do Sul. E-mail: cristiane. umbelino@hotmail.com

* Professor da Universidade Estadual de Mato Grosso do Sul. E-mail: danglei@uems. br 


\begin{abstract}
The project aim to discuss methodological and theoretical aspects related to the learning of african literature on portuguese literature within municipal schools in Campo Grande-MS. Our target will focus on the legislation destined to the teaching of literatures in portuguese language based on the Parâmetros Curriculares Nacionais, PCN (National Curriculum Parameters) at the Lei de Diretrizes e Bases da Educação Brasileira, LDB (Brazilian Education Guidelines); as well as the Elementary and Middle School Curriculum References of Mato Grosso do Sul. Secondly, we will be focusing on how the african literature on portuguese literature is handled at the texts directioned to the pedagogical making associated to the teaching of Literatures in Mato Grosso do Sul. We also are going to investigate all the actions developed towards the bettering of the teaching on African Literature in the last three years in Mato Grosso do Sul via discussion of the State Guidelines for the Middle School, giving special attention to the teaching of portuguese literature within the State. One of our main concerns is to verify the status on how the teaching of both literatures, african and portuguese, has being conducted.
\end{abstract}

Key words: Literary canon; African literature; Literature teaching

\title{
Introdução
}

Um dos temas mais discutidos na atualidade é a diversidade cultural na comunidade lusófona e a necessidade de inclusão de temas ligados à comunidade africana no processo de valorização da diversidade cultural brasileira. O Parecer $n^{\circ}$ 003/2004 do Conselho Nacional de Educação que estabelece as Diretrizes Curriculares Nacionais para a Educação das Relações ÉtnicoRaciais e Ensino de História e Cultura Afro-brasileiras e Africanas abre caminho para a valorização da cultura lusófona de expressão africana no interior do processo de ensino na Educação Básica e no Ensino Superior no Brasil. 
A proposta de investigação surge de uma inquietação crítica no que se refere ao ensino de Literaturas africanas em Língua Portuguesa no Brasil e, no caso específico deste projeto, em Mato Grosso do Sul. Verificaremos no PCNs, LDB e nos Referenciais Curriculares da Educação Básica e do Ensino Médio de Mato Grosso do Sul como este tema é tratado. As ações direcionam a atividades específicas de investigação. $\mathrm{O}$ investigador científico irá debruçar-se sobre as indicações metodológicas/teóricas direcionadas para o Ensino Fundamental e Médio e investigará as indicações específicas para o ensino de Literaturas africanas em Língua Portuguesa. As ações vinculam-se ao projeto de pesquisa "O Ensino de Literatura no Ensino Médio em Escolas da Rede Estadual de Ensino do Município de Campo Grande MS" e pretendem verificar quais açôes efetivas foram tomadas para a melhoria do ensino de Literaturas africanas no estado de Mato Grosso do Sul.

O projeto é justificado na medida em que propicia uma reflexão sobre o papel da literatura africana como refratária de fatores culturais da sociedade Lusófona, fato que possibilita a valorização de elementos culturais da África no Brasil. Seu principal objetivo é investigar a situação do ensino de literaturas africanas em língua portuguesa no município de Campo Grande/ MS, bem como a influência dos documentos oficias de ensino de literaturas em Língua Portuguesa no estado; bem como contribuir para o contato de um maior número de leitores com obras literárias produzidas na África.

\section{Situação da leitura literária: apontamentos}

Uma das principais propostas dos Parâmetros Curriculares Nacionais para o ensino de língua e literatura é promover a democratização do saber e a diversidade na abordagem dos gêneros discursivos em ambiente escolar, entendidos como heterogêneos. Ao interagir com os diferentes gêneros textuais/discursivos, o 
escrevente incorpora as modalidades organizacionais da linguagem e constrói o emaranhado de manifestações discursivas identificáveis na tradição da Língua Portuguesa (LP). O percurso sugerido nos PCN é propiciar o surgimento de autores, entendidos como produtores de textos e ou enunciados significativos. Ainda pensando nas orientaçôes dos PCN, o ensino de língua, visto como uma atividade ampla e diversificada, incorpora e valoriza as variantes regionais de utilização da linguagem, fato que garante a diminuição das fronteiras textuais e a democratização do aprendizado de competências linguísticas. A literatura, nesse contexto, seria um importante aliado do professor no processo de construção de textos significativos não só em termos linguísticos, ou seja, de competência textual, mas na possibilidade de produzir enunciados que dinamizem sua formação cultural e não só escolástica.

Ao valorizar organizações textuais coerentes e coesas, os PCN oferecem orientações ao professor. Estas orientações podem ser entendidas como linhas de reflexão que passam por conceitos advindos da Sociolinguística, Linguística Textual, Gramática Normativa, Sociologia da linguagem, Sintaxe, Morfologia, Análise do Discurso, Teoria Literária, Crítica literária, entre outras áreas da Linguística e dos Estudos Literários.

Nos PCN é possível verificar a preocupação em valorizar o texto literário como uma importante modalidade textual, não como único "modelo" textual de valor, mas como uma das faces da diversidade de produções linguísticas em LP. É um processo de democratização e, por que não dizer, de redimensionamento da aura de "abstração" que o texto literário adquire dentro das escolas. Sua importância, ainda na aresta dos PCN, está em deslocar o leitor da referencialidade do texto, conduzindo à valorização da linguagem como parte integrante do processo de amadurecimento humano e, nesse sentido, de aspectos políticoculturais evocados no leitor.

Compreendendo a validade dessa proposta, investigaremos a relação entre normas pedagógicas e a situação do ensino de 
literaturas africanas de expressão de Língua Portuguesa em Mato Grosso do Sul.

A metodologia utilizada no projeto será, em um primeiro momento, ligada a uma investigação bibliográfica que toma por base a leitura e análise do Parecer no 003/2004 do Conselho Nacional de Educação que estabelece as Diretrizes Curriculares Nacionais para a Educação das Relações Étnico-Raciais e Ensino de História e Cultura Afro-brasileiras e Africanas, dos PCN, da Lei de Diretrizes e Bases da Educação Brasileira (LDB); bem como dos Referenciais Curriculares da Educação Básica e do Ensino Médio de Mato Grosso do Sul em busca das diretrizes relacionadas ao ensino de literatura africana no interior dos referidos documentos.

A intenção é discutir a relação entre os documentos prescritivos e as ações direcionadas ao ensino de Literaturas em Língua Portuguesa em Campo Grande/MS por meio da investigação de alguns Livros Didáticos e de entrevistas a professores da E. E. João Carlos Flores em Campo Grande/MS. A principal preocupação é contribuir para a valorização do objeto literário e a formação de cidadãos conscientes da importância dos valores culturais e, mais especificamente, do objeto literário como parte integrante da cultura brasileira em sua relação com a comunidade lusófona.

\section{Informações sobre o ensino de literaturas africanas em documentos oficiais brasileiros}

Investigando informações específicas sobre o ensino de literaturas africanas em documentos oficiais iniciamos nosso percurso investigativo com a leitura dos Parâmetros Curriculares Nacionais - PCN. Entendemos que este documento constitui um conjunto de recomendações didático/teóricas para a abordagem do ensino de língua e literatura no ensino fundamental em todo 
o país fato importante dentro da investigação proposta e que justifica a escolha do documento.

No volume I - Introdução - o documento justifica e fundamenta as opções feitas para elaboração do documento indicando a necessidade de focalização das diferentes áreas em temas transversais. No volume II - Língua Portuguesa - o foco recai sobre a especificidade do texto literário a partir da sugestão de que a variedade literária é importante para a compreensão da cultura e seu ensino deve ser incorporado às práticas cotidianas em sala de aula. $\mathrm{O}$ documento, em linhas gerais propóe práticas de leitura que valorizem sua especificidade, como no trecho abaixo:

O trabalho com leitura tem como finalidade, a formação de leitores competentes e consequentemente a formação de escritores, pois a possibilidade de produzir textos eficazes, tem sua origem na prática de leitura, espaço de construção da intertextualidade e fontes de referências modalizadoras. A leitura, por um lado, nos fornece a matéria prima para a escrita: o que escrever. Por outro, contribui para a constituição de modelos: como escrever (BRASIL, 1998, p. 53).

No volume X - Pluralidade Cultura e Orientação Sexual - ao apresentar os Temas Transversais os PCN indicam a necessidade de abordar temas relacionados a cultura africana. Ocorre que o foco é a discussão de questôes relacionadas à formação e a relação da África na História do Brasil, dando enfoque a influência africana nos movimentos abolicionistas, bem como a contribuição histórica da África na formação do Brasil. A Literatura africana não é comentada diretamente, mas apresentada como fator importante na discussão da tradição oral e na influência na escrita via compilação de mitos, lendas, "causos" presentes na literatura de cordel e produção oral.

Nos três volumes dos PCN analisados não encontramos referências diretas ou a indicação da necessidade de estudos pormenorizados da Literatura Africana em língua Portuguesa, fato reconhecido como preocupante em nosso estudo, uma vez que indica um distanciamento dos PCN de questões específicas relacionadas ao ensino de literaturas africanas em Língua portuguesa no Brasil. 
Outro documento analisado foi a Lei de Diretrizes e Bases da Educação - LDB no 9.394 de 20 de dezembro de 1996, que estabelece as diretrizes e bases da educação nacional. Na seção IV destinada ao ensino médio, Art. 36, item I, p. 33 encontramos:

Destacará a educação tecnológica básica, a compreensão do significado da ciência, das letras e das artes; o processo histórico de transformação da sociedade e da cultura: a língua portuguesa como instrumento de comunicação, acesso ao conhecimento e exercícios da cidadania (BRASIL, 1996, p.33).

Uma das questões que nos parece preocupante é o fato de a literatura não ser tratada de forma singular, mas em um campo de maior abrangência. $\mathrm{O}$ ensino de literatura fica demarcado dentro da LDB como campo pertencente ao ensino de Língua Portuguesa e a ausência de referências diretas não só a especificidade do texto literário, mas a apresentação deste conteúdo como refratário da Língua embora seja positivo, aponta para um gradativo distanciamento da Literatura enquanto objeto de expressão cultural. $\mathrm{O}$ distanciamento fica mais evidente pela omissão de questões ligadas à literatura de expressão de Língua portuguesa em especial o ensino da Literatura Africana.

Pautado na LDB n ${ }^{\circ}$ 9.394, a Secretaria do Estado da Educação do Mato Grosso do Sul, apresenta o Referencial Curricular da Educação Básica em vigor até dezembro de 2011 e em processo de reformulação, conforme informação da Secretária Estadual de Educação, conteúdos a serem trabalhados na Educação Básica de forma dinâmica e objetiva.

No capítulo destinado a Língua Portuguesa segue a divisão por áreas de conhecimento. A primeira divisão do $1^{\circ}$ ao $3^{\circ}$ ano subdivide-se em tópicos de Linguagem, dando ênfase a conteúdos como Fonologia e Textualidade. Na página 32, no item primeiro bimestre do primeiro ano (e seguirá quase idênticos nos outros bimestres e anos) temos como conteúdos indicados: Linguagem: História da Língua Portuguesa - Língua e Linguagem - Níveis de Linguagem - Linguagem culta e coloquial - Variações Linguísticas - Dificuldades da Língua em uso.Fonologia: Orientações 
Ortográficas. Textualidade: Leitura, escrita, análise, interpretação e produção de texto.Gêneros Textuais. Tipos de textos e respectivos princípios organizacionais: narração, descrição e dissertação.

No capítulo destinado ao ensino de Literatura encontramos a mesma organização prescritiva observada no capítulo destinado ao ensino de Língua Portuguesa. Indica-se conteúdos seguindo o esquema: apresentação de Escolas de época como, por exemplo, Pré-Modernismo e Modernismo, e, posteriormente, a indicação de comentários sobre os principais autores e obras. Na página 43 no item segundo ano do terceiro bimestre apresenta-se os seguintes temas: Realismo em Portugal: Contexto histórico-social - Contexto literário - Características - Principais autores e obras.

Neste documento também como no PCN e na LDB encontramos a ausência de referência à diversidade da Literatura em Língua Portuguesa produzida na Africana, bem como um apagamento da importância específica do texto literário enquanto singular. Esta singularidade é apresentada apenas nos PCN, mas parece figurar como apêndice das inúmeras variedades textuais indicadas como objeto de ensino de linguagens neste documento.

Após a investigação nos documentos oficiais investigamos livros didáticos em busca de referências ao ensino de literaturas em Língua portuguesa produzidas na África. Selecionamos três autores diferentes para essa pesquisa, tendo como justificativa o fato de serem obras utilizadas como material de apoio pedagógico (MAP) em Mato Grosso do Sul, durante o ano letivo de 2011 e com indicadores de reedição pelas editoras, uma vez que os títulos constam na lista de obras didáticas recomendadas para seleção de Livros didáticos no PNDL. São eles: Lingua e Literatura, da autora Maria da Conceição Castro (Saraiva), Português - Palavrae Arte, Tania Pellegrini e Marina Ferreira (Atual) e Português Ensino Médio, de José de Nicola (Scipione).

O livro de Castro (1988) é organizado em três volumes. Apresenta uma relação independente entre Literatura, gramática e produção de texto. Na Literatura há um número de textos e fragmentos contextualizados para o ensino da mesma. No 
primeiro volume temos a apresentação de conceitos e características à Literatura, uma breve apresentação dos gêneros literários como Trovadorismo, Humanismo, Classicismo, Barroco e Neoclassicismo. Nesta apresentação são oferecidos excertos textuais e exercícios sobre os temas apresentados como pode ser visto na unidade 10 - Humanismo - página 246 , onde temos um fragmento de um dos textos mais conhecidos de Gil Vicente: "Farsa de Inês Pereira":

Vem Pero Marques e diz: Homem que vai aonde eu vou, não se deve de correr;ria embora quem quiser, que eu em meu siso estou. Não sei onde mora aqui: Olhai que meesqueci a mi!Eu creio que nesta rua, $\mathrm{E}$ esta parreira é sua, Já conheço que é aqui (CASTRO, 1988, p. 246).

A autora sugere que o texto seja lido por alguns alunos, representando cada personagem, para que se note as características dos mesmos. Uma maneira interessante de incentivo a prática de leitura em sala de aula, mas que foge a problematização mais profunda das características específicas do texto, bem como a uma contextualização mais detida sobre os valores cultuais por ele apresentado.

O segundo volume traz o Romantismo no Brasil e em Portugal, o Realismo e o Naturalismo no Brasil e Portugal, bem como informações historiográficas sobre o Parnasianismo e o Simbolismo. Na unidade 9, o Realismo e o Naturalismo no Brasil em sua página 267 o livro apresenta um trecho de Quincas Borba, romance de Machado de Assis. Neste fragmento, a autora apresenta o enredo, fazendo referência a ironia em Machado de Assis, diante das teorias filosóficas e científicas da época:

Não há morte. O encontro de duas expansões, ou a expansão de duas formas, pode determinar a supressão de uma delas; mas rigorosamente não há morte, há vida, porque a supressão de uma é a condição da sobrevivência da outra, e a destruição não atinge o princípio universal e comum (CASTRO, 1988, p. 267).

Ocorre no entanto, que a informação, embora relevante, aparece sem uma interferência analítica do texto sugerido o que 
dá uma informação estanque que indica memorização diante de um traço específico da obra machadiana, fato que impede a reflexão do leitor sobre o fragmento lido e da a impressão de uma totalidade diante não só do romance Quincas Borba, mas sobre a obra completa do autor que parece ser superficial e distanciada do contexto humano em sentido mais pragmático. No terceiro volume destinado ao Pré-modernismo e ao Modernismo brasileiro e suas fases e o Modernismo em Portugal o livro continua a apresentar informações descontextualizadas.

Na unidade 13, modernismo em Portugal temos o fragmento que segue: "Tão cedo passa tudo quanto passa! Morre tão jovem ante os deuses quanto Morre! Tudo é tão pouco! Nada se sabe, tudo se imagina. Circunda-te de rosas, ama, bebe, e cala. O mais é nada.” (CASTRO, 1988, p. 388).

A autora destaca nesse fragmento traços da personalidade de Fernando Pessoa e seus heterônimos e pede, no exercício proposto, que seja identificado a qual destes heterônimos pertence o fragmento por meio de características encontradas no poema à luz de um conjunto de características listadas na página 387. Este tipo de exercício é recorrente na obra de Castro (1988): listar características e solicitar a comprovação destas em fragmentos textuais posteriores. Embora indique a pesquisa sobre particularidades da obra de autores o exercício não faz comentários detidos sobre obras partindo sempre de apontamentos preestabelecidos o que, em nosso entendimento, restringe as informações sobre aspetos da obra literária a comentários fechados de pouca flexibilização.

Português: palavra e arte, de PELLEGRINI; FERREIRA (2011), outro livro investigado, é organizado em três volumes que apresentam os capítulos de Literatura, Gramática e Redação. Em Literatura, segundo as autoras, é englobado a brasileira e a portuguesa, propondo um entrelaçamento entre texto e contexto. Traz algumas noções básicas de teoria literária, passando por várias escolas literárias. Da Idade média até o Brasil no Pós-Modernismo. 
No volume I, Literatura - A segunda época medieval, na página 121 as autoras trazem as novelas de cavalaria, fazem uma pequena introdução, onde afirmam que elas surgem como o primeiro gênero literário ficcional em prosa, pois, para as autoras (2011, p. 121) "[...] as novelas de cavalaria...usam a fantasia e a imaginação, na elaboração das peripécias de seus heróis relatadas com muitos detalhes e realismo". São apresentadas imagens e pinturas, como o quadro de E. Burne Jones, - O último sono do Rei Artur, numa interpretação da famosa lenda. Alinhados a estas imagens os enredos básicos de "Amadis de Gaula", e de "A demanda do Santo Graal" são apresentadas por meio de resumos e informações cronológicas relacionadas ao tempo histórico no qual as obras são construídas.

Essa novela trata da busca (demanda) do Santo Graal, o cálice sagrado onde José de Arimatéia, recolheu o sangue de Cristo derramado na cruz.Esta busca é empreendida pelo rei Artur e os cavaleiros da Távola Redonda. Depois de muitas aventuras, o cálice finalmente surge para Galaaz, o mais puro de todos os cavaleiros. Misturam-se nessa novela as origens célticas e os valores cristãos, como pureza, sacrifício, castidade, representados pelo símbolo da comunhão, o cálice com o sangue de Cristo (PELLEGRINI; FERREIRA 2011, p. 123).

Na mesma página segue como indicação para leitura, um trecho que narra o encontro do cavaleiro Galaaz com uma donzela:

Aquele castelo chamava-se Brut e seria bem assentado se tivesse suprimento de água. O senhor daquele castelo era rei, e chamava-se Brutos, por amor daquele reis Brutos que povoara primeiro... E a filha de Del-rei Brutos, que era muito formosa contemplou longamente Galaaz e ele pareceu tão formoso e tão bem talhado que o amou de coração como nunca amou outra coisa no mundo, que não tirava dele os olhos. $\mathrm{E}$ quanto mais o fitava, mais nele se apegava e o amava... (PELLEGRINI; FERREIRA 2011, p. 123).

No segundo volume, página 235, temos o mesmo formato do volume anterior no que se refere a apresentação de obras literárias. Vejamos os comentários sobre o enredo de Dom Casmurro, que segue com um comentário de Antonio Candido. 
Como o livro é narrado por este (Bentinho), na primeira pessoa, é preciso convir que só conhecemos a sua visão das coisas[...]. Mas o fato é, que dentro do universo machadiano, não importa muito que a convicção de Bento seja falsa ou verdadeira, porque a consequência é exatamente a mesma nos dois casos: imaginária ou real, ela destrói a sua casa e a sua vida. E concluímos que neste romance, como noutras situaçôes de sua obra, o real pode ser o que parece real (CANDIDO apud PELLEGRINI; FERREIRA 2011, p. 123).

Mais uma vez, uma indicação para leitura na página 236 com um trecho do romance Dom Casmurro, que enfoca a personalidade de Capitu - Capítulo CXXIII - Olhos de ressaca:

[...] Enfim, chegou a hora da encomendação e da partida. Sancha quis despedir-se do marido, e o desespero daquele lance consternou a todos. Muitos homens choravam também, as mulheres todas. Só Capitu, amparando a viúva, parecia vencer-se a si mesma. Consolava a outra, queria arrancá-la dali. A confusão era geral. No meio dela, Capitu olhou alguns instantes para o cadáver tão fixa, tão apaixonadamente fixa, que não admira the saltassem algumas lágrimas poucas e caladas... (ASSIS, 1971, p. 324).

No terceiro volume, no capítulo 12, intitulado "A geração de 45: poesia" é apresentada seguindo o mesmo padrão: contexto histórico, apresentação de fragmentos textuais e comentários críticos também fragmentados. A focalização da obra poética de João Cabral de Melo Neto traz uma breve biografia do autor, alguns trechos de seus poemas como, por exemplo, "Tecendo a manhã", "O Ferrageiro de Carmona" e "Morte e vida Severina: auto de natal nordestino". Do primeiro livro do autor, Pedra do sono de 1942, se destaca o seguinte poema:

Não a forma encontrada como uma concha, perdida nos frouxos areais como cabelos; não a forma obtida em lance santo ou raro, tiro nas lebres de vidro do invisível; mas a forma atingida como a ponta do novelo que a atenção, lenta, desenrola, aranha; como o mais extremo desse frio frágil, que se rompe o peso,sempre de mãos enormes (MELO, 1942, p. 236). 
Outro autor investigado é Jose de Nicola - Português: Ensino Médio, também em três volumes. No volume I, temos a Arte Literária, os gêneros literários, Humanismo, Renascimento, Barroco, Arcadismo, entre outros. No capítulo 10, os estilos de época na era clássica: Arcadismo, na página 380, destaca-se o fragmento de Cartas chilenas - Carta IX. Em seguida temos perguntas sobre o fragmento, relacionadas à estética e interpretação.

A desordem, amigo, não consiste em formar esquadrões, mas sim no excesso. Um reino bem regido não se forma somente de soldados; tem de tudo: tem milícia, lavoura e tem comércio. Se quantos forem ricos e se adornarem das golas e das bandas, não teremos um só depositário, nem os órfăos terão tutores, quando nisto interessa igualmente o bem di império. Carece a monarquia dez mil homens de tropa auxiliar? Não haja embora de menos um soldado, mas os outros vão á pátria servir nos mais empregos, pois os corpos civis são como os nossos, que, tendo um membro forte e outros débeis, se devem, Doroteu, julgar enfermos (GONZAGA, apud NICOLA, 2009, p. 380).

No II volume Romantismo, Realismo e Naturalismo, Prosa no século XIX, teatro, Parnasianismo e Simbolismo. No capítulo 3 , a narrativa moderna, na página 308, Nicola nos mostra um conto extremamente conciso:

"De repente e mosca salta e pousa na toalha branca. Você a espanta, sem que voe - uma semente negra de mamão" (TREVISAN apud NICOLA, 2009, p. 308).

Logo abaixo do fragmento encontramos uma observação de Afrânio Coutinho:

"O contista oferece uma amostra, através de um episódio, um flagrante ou um instantâneo, um momento singular e representativo. Procura obter a unidade de impressão rapidamente, a custa da máxima concentração e economia de meios" (COUTINHO apud NICOLA, 2009, p. 308).

O III volume aborda entre outros, o Modernismo em Portugal, o Brasil antes da Semana da Arte Moderna, Brasil Lírica, Brasil - Prosa. No capítulo 4 - O Brasil de 1922 a 1930, na página 283, segue o poema: 
Moça linda bem tratada, três séculos de família, Burra como uma porta: um amor.

Grã-fino do despudor, esporte,ignorância e sexo, Burro como uma porta: Um coió.

Mulher gordaça, filó de ouro por todos os poros Burra com uma porta: Paciência...

Plutocrata sem paciência, nada porta, terremoto Que a porta do pobre arromba uma bomba.

ANDRADE, Mário de, op.cit. (ANDRADE, apud NICOLA, 2009, p. 283)

Neste livro não encontramos referências a obras da Literatura Africana em língua Portuguesa o que aponta para o distanciamento nos documentos investigados de questões relacionadas ao ensino de literaturas africanas. Pelos excertos apresentados chagamos a conclusão de que os Livros Didáticos investigados produzem um conjunto de citações descontextualizadas que, muitas vezes, optam por apresentar autores em um percurso distanciado da investigação dos textos literários em sua especificidade.

O distanciamento e a impossibilidade de discussões mais especificas face ao texto literário Stirctu sensu dificulta a apreensão de valores culturais. Quanto a literatura africana em Língua portuguesa os materiais didáticos investigados não trazem nenhuma referência a estas produções, dando destaque, como visto, a textos brasileiro e, em alguns casos, portugueses. Quando pensamos estes textos à luz da chamada lei da diversidade cultual encontramos um distanciamento considerável não se face a literatura afro-brasileira como e, principalmente, a discussão da cultura áfrica e seus desdobramentos na cultura brasileira.

A Lei 10.639 de janeiro de 2003 apresenta uma indicação de que sejam trabalhadas questóes relacionadas ao ensino da História e da cultura afro-brasileira, fato que, em nosso entendimento poderia ser muito produtivo quando da abordagem de textos literários de autoria africana. Optamos por transcrever a lei na íntegra: 
Altera a Lei no 9.394, de 20 de dezembro de 1996, que estabelece as diretrizes e bases da educação nacional, para incluir no currículo oficial da Rede de Ensino a obrigatoriedade da temática "História e Cultura Afro-Brasileira", e dá outras providências.

O PRESIDENTE DA REPÚBLICA Faço saber que o Congresso Nacional decreta e eu sanciono a seguinte Lei:

Art. $1^{\circ}$ A Lei no 9.394, de 20 de dezembro de 1996, passa a vigorar acrescida dos seguintes arts. 26-A, 79-A e 79-B:

"Art. 26-A. Nos estabelecimentos de ensino fundamental e médio, oficiais e particulares, torna-se obrigatório o ensino sobre História e Cultura Afro-Brasileira.

$\$$ lo O conteúdo programático a que se refere o caput deste artigo incluirá o estudo da História da Árica e dos Africanos, a luta dos negros no Brasil, a cultura negra brasileira e o negro na formação da sociedade nacional, resgatando a contribuição do povo negro nas áreas social, econômica e política pertinentes à História do Brasil.

$\$ 2$ o Os conteúdos referentes à História e Cultura Afro-Brasileira serão ministrados no âmbito de todo o currículo escolar, em especial nas áreas de Educação Artística e de Literatura e História Brasileiras.

\$ 3o (VETADO)”

"Art. 79-A. (VETADO)"

"Art. 79-B. O calendário escolar incluirá o dia 20 de novembro como Dia Nacional da Consciência Negra."

Art. 2o Esta Lei entra em vigor na data de sua publicação.

Brasília, 9 de janeiro de 2003; 182o da Independência e 115o da República.

\section{LUIZ INÁCIO LULA DA SILVA}

Cristovam Ricardo Cavalcanti Buarque

Este texto não substitui o publicado no D.O.U. de 10.1.2003 (BRASIL, 2003, p. 1)

A lei apresenta uma indicação da abordagem histórica sobre a cultura Afro-brasileira, e que estas questões deverão ser abordadas em especial nas áreas de Educação Artística, Literatura e História Brasileira. Tendo em vista a indicação da lei para a 
valorização da "cultura afro-brasileira" propomos uma pesquisa de campo em uma escola estadual, como forma de investigar como e se o professor que ministra as aulas de Literatura trabalha com a diversidade literária em Língua Portuguesa produzida na África, sobretudo para investigar se o quadro normativo apresentado na investigação dos documentos oficiais apresenta alguma mudança em ambiente escolar. Os comentários dos Livros didáticos, feitos até este momento da pesquisa, priorizaram a apresentação da organização destas obras que, em muito, fogem do enfrentamento direto do texto literário e da cultura "afrodescendente" e recorrem a citações de fragmentos não só textuais como críticos de maneira descontextualizada o que, em nosso entendimento, dá uma visão superficial da diversidade literária.

Lembramos que nosso objetivo é discutir o ensino de literaturas africanas em Língua Portuguesa em ambiente escolar e nossa conclusão, após a leitura dos livros didáticos investigados, é de que essa diversidade é ausente do conteúdo dos livros investigados. Nessa pesquisa observamos o trabalho do professor de Literatura e sua relação com os textos literários e a familiaridade de alunos e professores com a literatura, não só brasileira como a produzida na África Lusófona.

Optamos por investigar esta relação por meio de questionários que verificaram a forma como os textos literários são apresentados em ambiente escolar, objeto da próxima sessão deste trabalho.

\section{Discussão dos dados: entrevistas}

Diante deste distanciamento, nossa proposta para um segundo momento foi uma pesquisa de campo, na Escola Estadual João Carlos Flores, escolhida como lócus de investigação. A respeito dos entrevistados, mantivemos contato com a Coordenação Pedagógica, a Coordenação de área de Língua Portuguesa, professores de Literatura e alunos do primeiro ao terceiro ano do 
ensino médio. Os instrumentos de pesquisa utilizados foram um gravador e dois questionários elaborados. Todos os envolvidos não foram em nenhum momento obrigados a responder esses questionários. Após um primeiro contato com os docentes, os quais mostraram-se receptivos, a pesquisa foi realizada, com autorização da Secretária Estadual de Educação de Mato Grosso do Sul, conforme Ofício número 04/2012 de 29 de fevereiro do corrente ano. Segue o questionário destinado aos professores:

\section{Questionário1 - Professores/coordenadores}

1. Qual sua formação acadêmica?

2. Nos últimos anos participou de cursos e ou ações de aperfeiçoamento profissional que abordasse $(\mathrm{m})$ ou focalizasse $(\mathrm{m})$ especificamente o ensino de Literatura? Poderia mencionar quais foram?

( ) Sim ( ) Não

3. Em caso afirmativo: qual a importância desses cursos em sua atuação profissional para o ensino de literatura?

4. O senhor(a) trabalha ou conhece autores africanos de Língua portuguesa?
( ) Sim
( ) Não

5. Poderia comentar a resposta da questão 4. (em caso negativo ignorar a pergunta)

6. Você aborda e ou faz comentários em suas aulas de Literatura sobre a Literatura portuguesa ou de expressão em língua portuguesa na África?

7. Quais autores literários portugueses e africanos o senhor(a) conhece e indica para leitura?

8. Quantas obras literárias o senhor (a) leu nos últimos dois anos? Poderia informar os títulos? Poderia fazer algum comentário sobre a leitura indicada?

9. Qual é a carga horária semanal destinada especificamente ao ensino de Literatura? 
10. Qual, em sua opinião, a importância das aulas de literatura para o desenvolvimento de seu interesse pela leitura? Poderia comentar?

11. Você conhece a lei 10.639 de agosto de 2003?

12. Quais projetos específicos para a leitura literária foram desenvolvidos em sua escola nos últimos 03 anos?

13. Poderia comentar a importância destes projetos?

14. O material de Apoio Pedagógico que utiliza aborda a Literatura africana em Língua Portuguesa?

( ) Sim

) Não

Com essas questões, nossa intenção era a verificar o perfil do professor que ministra as aulas de Literatura, bem como suas concepções sobre o ensino da mesma e seu conhecimento referente a Literatura Africana em língua Portuguesa. Para preservar a identidade dos entrevistados adotamos a descrição de $\mathrm{Al}$ a $\mathrm{A} 3$ (para coordenadores); Bl a B3 (para professores); $\mathrm{Cl}$ a $\mathrm{Cl0}$ (para alunos).

Dos três coordenadores entrevistados, Al tem formação acadêmica de Magistério, A2 Pedagogia e A3 Letras/Inglês. Nenhum destes participou ultimamente de alguma atividade relacionada ao ensino de Literatura. Quanto a especificidade na Literatura Africana em Língua Portuguesa, os três responderam ter conhecimento que o tema estava no Referencial Curricular de 2012, mas não tiveram qualquer contato com essa Literatura, pois ela seria ministrada apenas no segundo bimestre do terceiro ano do ensino médio, mas sabem da existência da Lei 10.639. Com relação a outras literaturas, Al respondeu que seu tempo é escasso para leitura, tornando essa prática inviável no momento.

A2 informou que suas leituras resumem-se a temas ligados a questôes pedagógicas de ensino. A3 lê revistas e jornais eletrônicos quando possível. Indagados sobre a realização de projetos específicos de leitura literária, Al não soube responder, A2 e A3 citaram o livro Tosco do filósofo e psicólogo Gilberto Mattje - Editora Alvorada - 2009, que estava sendo trabalhado 
pelos professores. Segundo tais depoimentos, percebemos um grande distanciamento da coordenação, relativo as Literaturas em língua portuguesa, seus conhecimentos resumem-se apenas ao que traz o Referencial Curricular, fator predominante entre todos, e isso se dá também sobre a lei 10.639, todos já ouviram, porém nenhum a leu na íntegra.

Dos professores entrevistados, Bl tem formação acadêmica em Letras e não participou recentemente de atividades relacionadas ao ensino de Literaturas. Indagada sobre a Literatura africana, elegeu Macunaíma de Mario de Andrade, referindo-se as questões dos mitos do romance, citando a parte em que Macunaíma, entra no rio com seus irmãos e tornam-se coloridos, remetendo para a mesma, questões de ritos africanos. Citou também Menina Bonita do Laço de Fita de Ana Maria Machado, relatando - em suas palavras - a história de uma menininha negra, que quando perguntada, porque era tão pretinha, uma de suas respostas, fora porque caíra na tinta preta quando era pequenina.

Esclarece que os autores citados são brasileiros, mas que as histórias trazidas poderiam encaixar-se nessa categoria. Diz não ter muita certeza, mas crê não conhecer, nem ter lido algum autor africano e ainda não fez nenhuma referência sobre eles em suas aulas. Sobre a lei 10.639, disse apenas que a conhece. Quanto as obras literárias lidas ultimamente, diz ler em média de três a cinco livros ao ano. Lembrou-se de um livro de Poemas de Carlos Drummomd de Andrade, citando os poemas José, ao qual considera um clássico e sempre o trabalha em suas aulas de Literatura, Para Senpre, que fala sobre mãe e A Um Ausente. É seu autor preferido.

Citou também Manoel de Barros, que também gosta muito e já trabalhou em suas aulas, Retrato do Artista Quando Coisa. Relativo a importância das aulas de Literatura, considera essencial para o desenvolvimento e o interesse pela leitura, uma vez que é nesse contexto que os alunos entram em contato direto com a literatura. Sobre os projetos de leitura, desenvolvidos na 
escola, diz que sempre tem, porém não soube citar ou comentar sobre algum destes.

O professor B2 tem formação acadêmica em Letras - Inglês em 2007, na Universidade Estadual do Mato Grosso do Sul. Sobre os cursos de aperfeiçoamento em ensino de Literatura, diz ter feito alguns projetos quando estava na universidade, os quais abordavam principalmente o incentivo a leitura. Considera que essas ações foram relativas para sua atuação profissional, porém afirma ser difícil aplicá-las no dia a dia, pois o desinteresse dos discentes pela Literatura hoje é muito grande, mas que não se abala diante desse quadro, procurando sempre incentivá-los. Para isso, diz que a escola tem desenvolvido projetos de leitura, onde os alunos são levados a biblioteca, onde fazem uma exploração de autores, escolhidos de forma aleatória e que essa ação se repete uma vez na semana.

No momento estavam trabalhando com o Projeto Tosco. Perguntada sobre quantas obras literárias leu ultimamente, o professor B2 assim respondeu: “...Eu poderia maquiar sua pesquisa e citar vários autores e livros, os quais li na universidade. Mas vou the mostrar a realidade do professor. Quando chegamos em casa, nos deparamos com três situações distintas, que são a família e seus assuntos particulares, a segunda o trabalho levado na "bagagem", provas para corrigir, aulas para preparar e a terceira os livros na estante. Qual você acha que escolho? Naturalmente faço a primeira, e obrigatoriamente faço a segunda, e que fique claro que não foi uma escolha,e sim uma consequência, ficando a terceira, a leitura, impossível de ser realizada. E garanto que você (dirigindo-se a essa pesquisadora) quando se formar e entrar para a escola encontrará a mesma situação...”.

Quanto a Literatura em Língua Portuguesa produzida na África, recorda-se de alguns autores que leu também na universidade, como Mia Couto e Pepetela, porém não sabe mencionar nenhuma das leituras. Ainda não aborda esses escritores em sala de aula, pois afirma que mediante o Referencial Curricular que servirá de apoio para o encaminhamento dessa matéria, ela entrará 
em contato com essa Literatura, até então, não explorada. Comentou a lei 10.639, como sendo de extrema importância para a inclusão de temas africanos no universo escolar, pois considera que a questão da etnia deva ser exaustivamente discutida em todos os níveis.

O professor B3 tem formação acadêmica em Letras no ano de 1985. Não participou recentemente de cursos que focalizassem o ensino de Literaturas. Sobre sua relação com a Literatura, diz ler em média três livros nos últimos anos, também não recorda-se dos nomes dos autores, pois acha que já está com a "memória fraca”. Citou apenas um título, Recordações da Casa dos Mortos de um autor que ela acha ser russo, e que é bem conhecido, mas não sabe o nome. Segundo a mesma, foi a partir deste livro, que é muito importante, que começaram a trabalhar mais com a Psicologia, pois relata a história de pessoas que cometeram todos os tipos de crimes e foram confinados todos juntos, esperando a morte. Diz ter gostado muito desta obra.

Sobre importância das aulas de literatura para o desenvolvimento do interesse pela leitura, respondeu que depende muito de como é trabalhada a Literatura, por que os alunos leem se for feito algo dinâmico, pois assim eles se interessam mais, exemplificando com um debate, um júri. Com relação aos projetos que a escola tem para o desenvolvimento dessa leitura, o entrevistado diz que a escola faz todos os anos vários projetos, que são leitura de paradidáticos, leitura para pesquisa, para trabalho e o projeto Tosco. E que a Coordenação estava trabalhando muito com isso.

Perguntado sobre a Literatura Africana em Língua Portuguesa, respondeu que leu alguns poemas africanos, mas não recorda-se dos autores nem consegue comentar uma dessas leituras. Não abordou ainda o tema e/ou autores africanos em suas aulas, mas irá começar em breve, pois está no Referencial Curricular. Sobre a Lei 10.639, respondeu que talvez tenha lido a respeito, mas não recorda-se no momento, não se ateve ao assunto.

Fazemos agora a compilação dos dados das entrevistas feitas com os alunos. Segue o questionário a eles aplicado: 


\section{Questionário 2 - Alunos}

1. Você gosta de literatura?

2. Quantos livros você leu nos últimos dois anos?

3. Poderia comentar alguma das leituras?

4. Você conhece autores literários Portugueses e/ou africanos em Língua Portuguesa ou apenas brasileiros?

5. Caso conheça algum autor literário português ou africano, poderia indicar o nome e a obra que conhece?

6. Qual (is) autor(es) ou obra(s) você mais gosta? Poderia comentar?

7. Qual, em sua opinião, a importância das aulas de literatura para o desenvolvimento de seu interesse pela leitura? Poderia comentar?

Dos dez alunos entrevistados, quatro foram enfáticos em responder que não gostam de Literatura. Cl justificou que ler não serve para nada, e não acha que tais aulas são importantes para o desenvolvimento da leitura. A justificativa de $\mathrm{C} 4$ foi que gosta apenas das exatas, e desconsidera totalmente as aulas de Literatura, não sendo importantes para o desenvolvimento da leitura. Acredita que no lugar dessas aulas, e das de Filosofia, deveriam ter mais de matemática, porque todos devem aprender todas as operaçốes e a raciocinar.

C3 lê por obrigação, e diz que a única importância das aulas são para passar de ano. Todos os quatros não leram nada ultimamente, não podendo comentar sobre nenhuma leitura ou autor. Porém C3, lembrou-se de uma escritora que gostava,Clarice Lispector, porém quando perguntada, sobre qual obra sua teria lido, respondeu que lia frases da autora postadas na rede de relacionamentos FaceBook. C5 respondeu apreciar muito as aulas de Literatura, e que ajudam bastante no desenvolvimento e no interesse, mas não conseguiu citar livros ou autores, porque a professora não havia passado nada para ler. 
C6, também demonstrou gostar, disse que lê com mais frequência revistas e jornais, citando Isto é, e o O cortiço de Aluísio Azevedo, mas também não conseguiu comentar sobre.C7, C8, C9 e C10 responderam que gostam muito de ler, em média de 03 a 06 livros ao ano. C7 considera a importância das aulas de Literatura para o interesse pela leitura, por que é por meio dela que conhecemos este mundo literário. C8 considera um grande incentivo, C9 diz que as aulas sempre ajudam a entender e interpretar melhor os textos.

C10 diz que desenvolve principalmente o intelecto do aluno, porque quanto mais se lê, mais conhecimento se tem, e vai sempre adquirindo uma necessidade de informação.e aprendizado, salientando que deveriam haver mais aulas de Literatura. Perguntados sobre autores e obras, C7 cita Cara Pintada de Renato Tapajós, onde a história é cheia de ação, indo para outras épocas, inclusive na ditadura, sendo eleito o melhor livro lido até o momento. C8 fala de Meninos sem Pátria, de Luiz Puntel, conta a história de meninos que tem que deixar seu país, fala de exílio e que a professora pediu para fazer um resumo. Cita Clarice Lispector, porém conhecida também pelo Facebook.

C9 elege 03 autores, Dan Brown, Zibia Gaspareto e Augusto Cury e respectivamente os livros O Código da Vinci, O Amor Venceu e Ninguém é de Ninguém e $O$ vendedor de sonhos. Sendo o último enfatizado pelo entrevistado, como o melhor, porque mistura a ficção com lições para a vida. Comentou também as outras leituras. C10 fala sobre Literatura Fantástica, que explica como sendo algo de mitologia, onde é criado um universo nesse livro que nunca condiz com a realidade. Eduardo Spohr, J.R.R Tolkien e Lauren Kate estão na lista de seus preferidos com os livros Batalha do Apocalipse e Filhos do Éden de Spohr, O senhor dos Anéis e Silmarillium de Tolkien e A Tormenta de Kate. Discorreu um breve resumo sobre todos os livros citados.

De todos os alunos entrevistados, nenhum conhece ou já estudou algum autor africano em Língua Portuguesa, porém 
C9 entende Nelson Mandela como tal, dizendo ter assistido documentários sobre a África.

\section{Considerações finais}

No levantamento realizado, é possível perceber que os professores têm dificuldades em relação ao contato com a Literatura. Fatores como falta de tempo, falta de maiores expectativas dos alunos perante a disciplina, foram apontados como causas para este distanciamento. Sua dedicação ao estudo literário e a leitura fica comprometida em muito pela organização do tempo destinado ao ato específico da leitura, principalmente em relação aos textos lusófonos. Este fato é entendido, nos limites da pesquisa, como preocupante, pois fica a impressão de que Literatura não é leitura e sim um gênero de pouco valor dentro da sala de aula. Esta variedade linguística, entendida como gênero, acaba sendo desprestigiada por representar uma tangente não pragmática de uso de linguagem.

Entendemos que o distanciamento não só de alunos como de professores em relação aos textos literários, não só africanos; mas também brasileiro é fator importante para a desvalorização do objeto literário em ambiente escolar. Quanto a Literatura Africana em Língua Portuguesa, a situação é preocupante. Pelos dados da pesquisa fica evidente o distanciamento do público investigado diante o objeto literário e, mais especificamente, de textos africanos em Língua Portuguesa. Ao serem perguntados sobre o tema, a maioria dos ouvidos na entrevista entende por outro viés, entrando no âmbito de questões de raça e etnia e fugindo de descrições específicas da diversidade literária.

Entendemos que o ensino de literatura como uma maneira eficaz de conhecer novas vozes até então marginalizadas no ensino de literatura de expressão de Língua Portuguesa forneceria aos professores e alunos da Educação Básica uma possibilidade de 
compreensão mais ampla da cultura africana e, por correlação, as proximidades e distanciamentos diante da cultua brasileira.

Compreendemos as dificuldades quanto ao ensino da Literatura em Língua Portuguesa em um espaço de tempo reduzido na grade curricular - uma aula semanal. Não é tarefa fácil o enfrentamento com os textos africanos que são poucos divulgados em um contexto mais amplo, bem como as limitações dos professores quanto ao acesso a essa diversidade. Tendo que trabalhar com uma carga horária tão reduzida na disciplina de Literatura, já engessada nas aulas de Língua Portuguesa não é de estranhar que não só a literatura brasileira fique restrita a informações reducionistas como resumos e biografias de autores. Entendemos que esse distanciamento quanto a produção literária em Língua Portuguesa é resultado de um progressivo distanciamento dos leitores do objeto literário como um todo, algo muito preocupante e um dos resultados explícitos nesta pesquisa.

Não temos a expectativa de "criar soluções" que se apliquem como regra ás salas de aula; antes criar um diálogo entre professores e alunos que, em nível profundo, possa contribuir para a ampliação do debate sobre a necessidade de valorização do objeto literário no ambiente escolar o que, em nosso entendimento, possibilita reflexões sobre a importância do literário como espaço de expressão cultural.

\section{Referências}

ABDALLA JÚNIOR, Benjamin. Literatura, história e política: literaturas de língua portuguesa no século XX. São Paulo: Ática, 1989.

ABDALLA JÚNIOR, Benjamin. Orlanda Amarilis, Literatura de migrante. Dossiê Via. Paris, 2000.

ADAMODJY, Bahassan. Milandos de um sonho. Lisboa: Quetzal Editores, 2001.

ANDERSON, Benedict. Nação e consciência nacional. Tradução Lélio Lourenço de Oliveira. São Paulo: Ática, 1989. 
ANDRADE, Mário Pinto de. (Org.). Antologia temática de poesia africana 1: na noite grávida de punhais. Lisboa: Sá da Costa, 1975.

ANDRADE, Mário Pinto de. (Org.). Caderno de poesia negra de expressão portuguesa. Linda-a-Velha: África Editora, 1982.

APA Lívia, et al. Poesia africana de língua portuguesa. Rio de Janeiro: Lacerda Editores, 2003.

APPIAH, Kwame anthony. Na casa de meu pai: a África na filosofia da cultura. Rio de Janeiro: Contraponto, 1997.

AUGEL, Moema Parente. O desafio do escombro: a literatura guineense e a narração da nação. 2005. Tese (Doutorado em Literaturas de Língua Portuguesa) - Faculdade de Letras. Universidade Federal do Rio de Janeiro, Rio de Janeiro, 2005.

BARBEITOS, Arlindo. Angola angolê angolema. Lisboa: Sá da Costa, 1977.

CABRAL, Amílcar. Apontamentos sobre a poesia cabo-verdiana. obras escolhidas. Lisboa: Seara Nova, 1976. v. 1, p. 25-29.

CAHEN, Michel. Lê Monzambique: une nation africane de langue officielle portugaise? Revue Canadienne dês Estudes Africaines, v. 24, n. 3, Toronto, 1990.

CHABAL, Patrick. Vozes moçambicanas: literatura e nacionalidade. Lisboa: Veja, 1994.

CHAVES, Rita de Cássia Natal. Angola e Moçambique: experiência colonial e territórios literários. São Paulo: Ateliê Editorial, 1999.

CHAVES, Rita et al. Boaventura Cardoso: a escrita em processo. Luanda: União dos Escritores Angolanos. São Paulo: Alameda, 2005. p. 89-107.

CHAVES, Rita; MACEDO, Tânia. Caminhos da ficção da África portuguesa. Vozes da África - Revista Biblioteca Livros, São Paulo, n. 6, p. 44-51, 2007.

COSTA ANDRADE, Fernando da. Literatura angolana (opiniões). Lisboa: Edições 70, 1980.

COSTA, José Francisco. Poesia africana de língua portuguesa. Cronópios, Literatura e Arte no Plural. São Paulo: Bitnick Comunicação Online Ltda, 
5/4/2006. Disponível em: <http//www.cronopios.com.br/site/ensaios>. Acesso em: 05 abr. 2011.

ERVEDOSA, Carlos. Roteiro da literatura angolana. 4. ed. Luanda: União dos Escritores Angolanos, 1974.

FARIA, Maria Alice. Parâmetros curriculares e literatura: as personagens de que os alunos realmente gostam. São Paulo: Contexto, 1999.

FERREIRA, Manuel. Literaturas africanas de expressão portuguesa. Lisboa: Biblioteca Breve; Instituto de Cultura e Língua Portuguesa, 1986. $2 \mathrm{v}$.

FERREIRA, Manuel. No reino de Caliban. Lisboa: Seara Nova; Plátano, 1985.

FERREIRA, Manuel. O discurso no percurso africano I. Lisboa: Plátano, 1989.

FINNEGAN, Ruth. Oral literature in África. Nairobi: Oxford University Press, 1977.

HAMILTON, Russell G. Literatura africana, literatura necessária, I: Angola. Lisboa: Edições 70, 1981.

HAMILTON, Russell G. Literatura africana, literatura necessária, II: Moçambique, Cabo Verde, Guiné-Bissau, São Tomé e Príncipe. Lisboa: Edições 70, 1984.

ILARI, R. A linguística e o ensino de Língua portuguesa. São Paulo. Martins Fontes, 1986.

LAJOLO, Marisa. Do mundo da leitura para a leitura do mundo. São Paulo: Ática, 1993.

LAJOLO, Marisa. Usos e Abusos da Literatura na Escola: Bilac e a Literatura Escolar na República Velha. Rio de Janeiro: Globo, 1982.

LARANJEIRA, Pires. De letra em riste: identidade, autonomia e outras questões. Lisboa: Edições Afrontamento, 1992.

LEÃO, Ângela. Contatos e ressonâncias nas literaturas africanas de lingua portuguesa. Belo Horizonte: Ed. PUC Minas, 2003.

LEITE, Ana Mafalda. Oralidades e escritas nas literaturas africanas. Lisboa: Edições Colibri, 1998. 
MARGARIDO, Alfredo. Estudos sobre literatura das nações africanas de língua portuguesa. Lisboa: A Regra do Jogo, 1980.

MARGARIDO, Alfredo. Poetas de São Tomé e Príncipe. Lisboa: CEI, 1980.

MATA, Inocência. Literatura angolana: silêncios e falas de uma voz inquieta. Lisboa: Mar Além, 2001.

MATOS, Alexandre Valente de. Provérbios macuas. Instituto de Investigação Cientifica Tropiacal, Lisboa, 1982.

MENDONÇA, Fátima. A literatura moçambicana em questão. Discursos: estudos de língua e cultura portuguesa. Lisboa: Universidade Aberta, fev. 1995.

PARREIRA et al. Veredas de Rosa. Belo Horizonte: Editora PUC Minas, 2000.

PATRAQUIM, Lúis Carlos. Monção. Lisboa: Edições 70, 1980.

ROCCO, Maria Thereza Fraga. Literatura/ensino: uma Problemática. São Paulo: Ática, 1981.

ROCHA, Jofre. Geração de 50: percurso literário e sua importância na luta de libertação de Angola. Scripta, Belo Horizonte, v. 1, n. 1, p. 220225, 1997.

ROSÁRIO, Lourenço do. A narrativa africana de expressão oral. Lisboa e Luanda: ICALP/Angolê - artes e Letras, 1989.

SAID, Edward. Cultura e imperialismo. Tradução Denise Bottman. São Paulo: Companhia das Letras, 1995.

SAID, Edward. Orientalismo: o Oriente como invenção do Ocidente. Tradução Tomás Rosa Bueno. São Paulo: Companhia das Letras, 1990.

SAID, Edward. Representations of the intellectual. London: Vintage, 1994. (The 1993 Reith Lectures).

SANTILLI, Maria Aparecida. Africanidade. São Paulo: Ática, 1985.

SANTOS, Elsa Rodrigues do. As máscaras poéticas de Jorge Barbosa e a mundividência caboverdiana. Lisboa: Caminho, 1980. 
SECCO, Carmen Lúcia Tindó Ribeiro. A magia das letras africanas: ensaios escolhidos sobre literaturas de Angola, Moçambique e alguns outros diálogos. Rio de Janeiro: ABE Graph, 2003.

SECCO, Carmen Lúcia Tindó Ribeiro. Eroticus moçambicanus: Virgílio de Lemos \&

SEPÚlVEDA, Maria do Carmo; SALGADO, Teresa (Org.). África \& Brasil: letras em laços. 2. ed. São Paulo: Yendis, 2006.

SILA, Abdulai. Mistida. Bissau: Ku Si Mon, 1997.

SILVA, Manuel de Souza. Do alheio ao próprio: a poesia em Moçambique. São Paulo:

SOUZA, Noémia. Sangue negro. Maputo: AEMO, 2002.

TABORDA, Terezinha. $O$ vão da voz: a metamorfose do narrador na ficção moçambicana. Belo Horizonte: PUC Minas, 2005.

TRIGO, Salvato. Introdução à literatura angola de expressão portuguesa. Lisboa: Brasília, 1977.

VENÂNCIO, José Carlos. Literatura e poder na África lusófona. Lisboa: Instituto de Língua e Cultura Portuguesa, 1992.

VIEIRA, José Luandino. O livro dos rios. Luanda: Nzila, 2006.

ZILBERMAN, Regina (org.). A Produção Cultural para a Criança. Novas Perspectivas 3. Porto Alegre: Mercado Aberto, 1982.

ZILBERMAN, Regina (org.). Leitura em Crise na Escola: as Alternativas do Professor. Novas Perspectivas 1. Porto Alegre: Mercado Aberto, 1982 